\title{
O ENSAIO DE CARACTERIZAÇÃO PARA ESCALONAMENTO DE MOINHOS PELO MÉTODO DE AUSTIN*
}

\author{
Claudio Luiz Schneider ${ }^{1}$ \\ Thaís Ferreira Marks Brasil Duque ${ }^{2}$
}

\section{Resumo}

Não existe na literatura formal uma descrição dos ensaios de caracterização necessários para a correta determinação de parâmetros de balanço populacional para escalonamento pelo método de Austin. As rotinas envolvidas são normalmente aprendidas em Universidades e Centros de Pesquisa que contam com engenheiros e/ou pesquisadores especificamente treinados para estes experimentos. Isso faz com que estes sistemas modernos sejam pouco utilizados na engenharia e restringe sua aplicação. Este artigo tem por objetivo estabelecer os procedimentos envolvidos na caracterização de processos de moagem e fomentar a utilização de técnicas modernas de escalonamento de moinhos de bolas nas empresas.

Palavras-chave: Escalonamento; Cominuição; Moagem; Caracterização.

\section{THE CHARACTERIZATION PROCEDURE FOR AUSTIN'S BALL MILL SCALE-UP SYSTEM}

\section{Abstract}

There is no formal literature describing the characterization tests that are required for the correct determination of population balance model parameters for Austin's scaleup procedure. The routines involved are normally learned in Universities and Research Centers that count with engineers or researchers specifically trained in these procedures. As a consequence, these modern scale-up systems are seldom used in routine engineering. It also restricts its use for the most common applications. This paper is aimed at establishing the procedures involved in the characterization of comminution processes and to broadcast the utilization of modern scale-up techniques to the mining companies.

Keywords: Scale-up; Comminution; Grinding; Characterization.

1 Engenheiro de Minas, PhD., Tecnologista Sênior, Coordenação de Processos Minerais, Centro de Tecnologia Mineral, Rio de Janeiro, Rio de Janeiro, Brasil.

2 Engenheira Química, M.Sc. (em andamento), Colaboradora, Coordenação de Processos Minerais, Centro de Tecnologia Mineral, Rio de Janeiro, Rio de Janeiro, Brasil. 


\section{INTRODUÇÃO}

O método de escalonamento de moinhos de bolas (e de moinhos AG/SAG) atribuído ao Prof. Leonard G. Austin [1] é essencialmente baseado em uma caracterização em moinho de laboratório, visando determinar parâmetros que descrevem a taxa de moagem em função do tamanho de partícula e a função quebra. Estes parâmetros são característicos do material, e podem ser determinados em um ensaio de moagem de pequena escala, em batelada.

Não existe um ensaio padrão de Austin, por assim dizer, e os ensaios podem ser realizados em moinhos de diversos tamanhos e diferentes razões $\mathrm{D} / \mathrm{L}$, e com cargas de bolas (carregamento J) diversas. É importante saber que não é possível especificar todas as quantidades e os tempos de moagem envolvidos numa série de ensaios, porque cada ensaio em um moinho é diferente e cada material testado é diferente também. A descrição dada aqui permite fazer os cálculos necessários para qualquer sistema e qualquer material, e usa alguns ensaios preliminares para decidir os tempos corretos do ensaio. Os métodos são concebidos para usar o mínimo de amostra e o mínimo de ensaios necessários para obter uma descrição detalhada do comportamento de moagem de um material normal, homogêneo e friável, como o minério de ferro, a fim de detectar qualquer comportamento anormal durante a moagem.

Os resultados são expressos como as taxas específicas de moagem sob as condições de ensaio e as funções de distribuição de quebra primária, como uma função do tamanho das partículas (geralmente o tamanho da peneira). A nomenclatura utilizada é a mesma proposta no texto "Process Engineering of Size Reduction: Ball Milling" por Austin, Klimpel e Luckie, porém os termos serão explicados à medida que eles ocorrem no texto. Exemplos são utilizados ao longo do texto, em geral de um minério de ferro, de forma a facilitar o entendimento.

Vale salientar que este artigo não é sobre o método de escalonamento em si, mas sim sobre o ensaio de caracterização que é requerido pelo método de escalonamento. Com o ensaio realizado, duas etapas completam o método de escalonamento, sendo uma a determinação dos parâmetros e a etapa final o escalonamento propriamente dito.

\section{O ENSAIO DE CARACTERIZAÇÂO}

\subsection{Teste de Moagem}

Assume-se que o moinho de teste é pequeno, cilíndrico, horizontal e de aço que opera a uma velocidade de rotação controlada. O moinho deve ter levantadores de carga horizontais de barras quadradas de cerca de 7 a $10 \mathrm{~mm}$. Para um moinho típico de diâmetro interno de 250 milímetros deveria haver oito levantadores igualmente espaçados. As paredes das extremidades devem ser lisas. Quanto às dimensões internas, a relação comprimento/diâmetro deve ser aproximadamente unitária ou maior que 1, ou seja diâmetro $\leq$ comprimento. Quanto menor o moinho, menor a demanda de amostra, ou seja, para os casos onde não há disponibilidade de amostras um moinho menor deve ser utilizado. Um moinho do tipo utilizado nestes ensaios de caracterização é mostrado na Figura 1, a título de ilustração. 


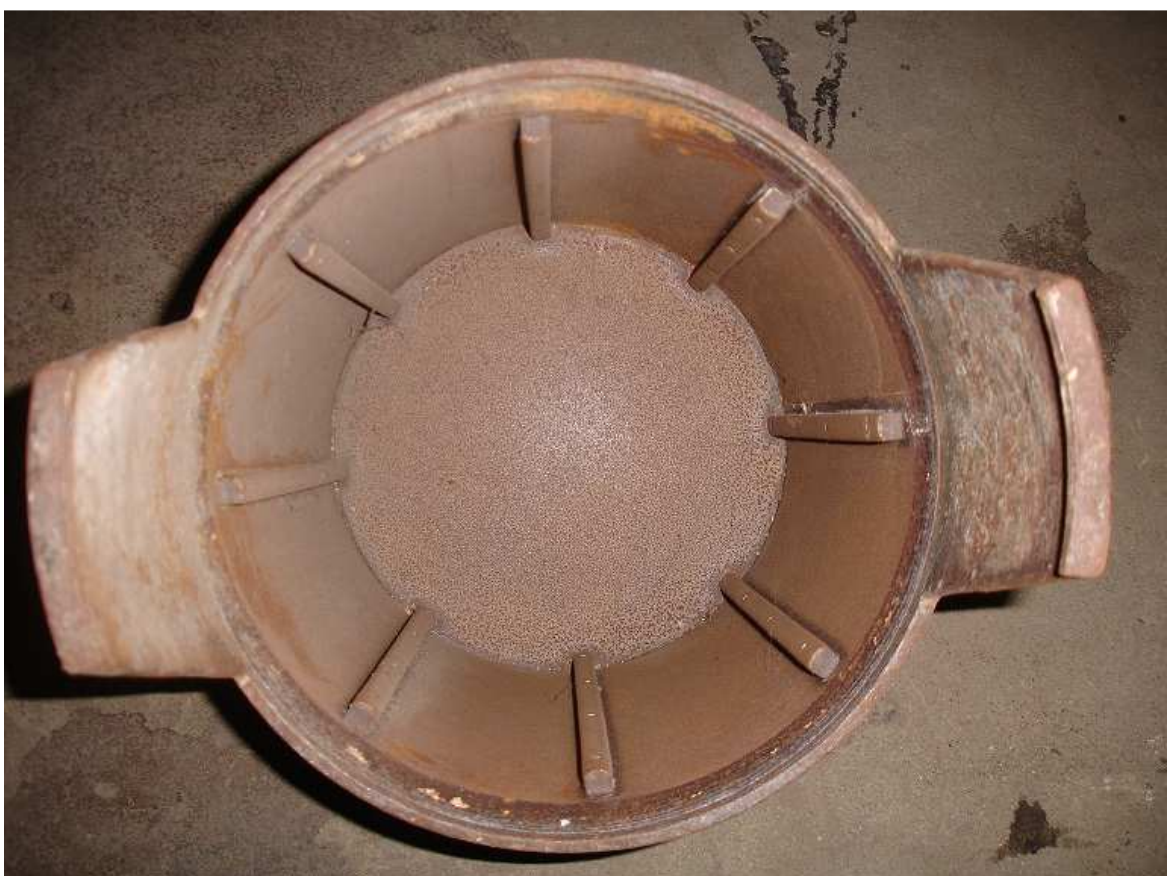

Figura 1: Um moinho utilizado para ensaios de moagem. Os levantadores de carga estão dispostos corretamente. A borda de encaixe da tampa contém um o-ring para vedação em ensaios a úmido.

A velocidade de rotação do moinho deve ser em torno de $70 \%$ da velocidade crítica definida por:

$$
\text { Velocidade crítica }\left(\text { em rpm) }=\frac{42,2}{\sqrt{\text { diâmetro interno do moinho-diâmetro das bolas }}}\right.
$$

O diâmetro das bolas deve ser aproximadamente $1 / 10$ do diâmetro interno do moinho. As bolas devem ser esferas perfeitas de ligas de aço polido (esferas de rolamento). É praxe utilizar uma carga de bolas igual a $20 \%(J=20 \%, J=0,2)$ do volume do moinho $(\mathrm{V})$. Esse valor é calculado assumindo uma porosidade do leito de bolas igual a 0,4. Conhecendo a densidade do aço das bolas, o peso das esferas deverá ser o mais próximo possível de:

\section{Peso das bolas (em gramas) $=J V[0,6($ densidade das bolas $)]$}

onde: $\boldsymbol{J}=\mathbf{0}, 2$ e $V$ em $\mathrm{cm}^{3}$.

A vantagem de se utilizar cargas de bolas de $20 \%$ é, novamente, menor demanda de amostra, quando comparado com cargas de $30 \%$ e até $40 \%$. Nada impede que cargas diferentes sejam utilizadas e qualquer valor entre 20 e $40 \%$ é aceitável.

A densidade aparente de um material (no nosso exemplo um minério de ferro) de granulometria entre $1,18 \times 0,85 \mathrm{~mm}$ é determinada através da adição de um peso conhecido de material em uma proveta graduada, agitando algumas vezes para 0 material assentar, e medindo-se o volume do leito de partículas formado.

O peso do material a ser utilizado em cada teste de moagem é calculado usando um enchimento dos interstícios do leito de bolas em repouso $U$ igual a 0,5.

\section{Peso do material (em gramas) $=U[0,4 J V($ densidade aparente do material $)]$}

Onde: $J=0,2, U=0,5$, densidade aparente em $\mathrm{g} / \mathrm{cm}^{3}$ e $V$ em $\mathrm{cm}^{3}$. Este mesmo peso é usado para todos os tamanhos de partículas. 
No nosso exemplo, um moinho de $250 \times 250 \mathrm{~mm}$ é utilizado com uma carga de esferas de rolamento de $25 \mathrm{~mm}$. A densidade do aço das esferas foi medida e é igual a $7,77 \mathrm{~g} / \mathrm{cm}^{3}$. A densidade aparente das partículas na faixa 1,18 x 0,85 mm é igual a 2,36 $\mathrm{g} / \mathrm{cm}^{3}$. Nestas condições a massa da carga de bolas deve ser de $12 \mathrm{~kg}$ e a massa de alimentação deve ser de $2,43 \mathrm{~kg}$. A velocidade de rotação do moinho foi calculada em 62 RPM.

\subsection{Preparação da Amostra}

Os tamanhos das partículas do minério se encontram na série de peneiras alternada $(\sqrt{ } 2)$. Os tamanhos escolhidos não são cruciais, mas devem ser proporcionais ao diâmetro das bolas de moagem. Em geral quatro tamanhos de partículas são testados. No nosso exemplo o material é relativamente tenaz com WI em torno de $12 \mathrm{kWh} / \mathrm{t}$. Nestas condições espera-se que a região de quebra anormal esteja localizada em tamanhos acima de $1 / 10$ do diâmetro das bolas, ou seja, partículas maiores que 2,5 mm. Quando a região de quebra anormal deve ser caracterizada, é necessário que pelo menos um dos tamanhos escolhidos esteja na região de quebra anormal. No nosso exemplo escolhemos partículas de 3,35x2,36 mm. Deve-se levar em consideração que, se o tamanho escolhido for muito grande, a premissa de quebra de primeira ordem pode ficar inválida, e por este motivo não se deve testar partículas maiores que $1 / 5$ do diâmetro das bolas. No nosso exemplo um segundo tamanho deve ser testado em torno do máximo da função seleção, 1,70x1,18 mm. Obviamente é impossível saber onde estará o máximo da função seleção antes de realizar os testes, mas escolhas bem criteriosas evitam que outras partículas tenham de ser preparadas. Outros dois tamanhos os quais espera-se estejam na região de quebra normal, para produzirem uma medida acurada da inclinação da função seleção nesta região, são necessários. No nosso exemplo, 1,18x0,850 mm e $0,425 \times 0,300 \mathrm{~mm}$. Pode ser necessário testar tamanhos adicionais, por isso, quando as amostras dos ensaios são preparadas, é conveniente guardar parte do material para um peneiramento adicional a fim de se obter resultados para outros tamanhos de partículas.

A análise dos resultados pode indicar que outros tamanhos sejam testados. Em geral, quatro tamanhos escolhidos de forma inteligente são suficientes para caracterizar as funções seleção e quebra. Para aplicações de remoagem e alguns outros casos, onde a região de quebra anormal pode ser desprezada (diâmetro da bola de reposição muito maior que o top size da alimentação), a escolha dos tamanhos é muito facilitada e o número de tamanhos testados pode ser menor. Existem ainda os casos onde o engenheiro propositadamente escalona o moinho para trabalhar somente na região de quebra normal, e, neste caso, o escalonamento é restrito a um top size de alimentação proporcional ao diâmetro da bola de reposição.

Acima, o WI foi utilizado como um indicador de tenacidade. No entanto, vale lembrar que o WI é um parâmetro de escalonamento derivado de um ensaio cíclico de moagem em circuito fechado [2], e usá-lo como indicador de tenacidade nem sempre funciona de forma satisfatória. Em geral, o WI não se correlaciona bem com outras propriedades mais fundamentais de tenacidade e quebra de minérios. Já o parâmetro GPR do ensaio de Bond é um parâmetro que apresenta correlação maior, mas quase nunca é utilizado para estes fins.

As partículas preparadas devem conter no máximo $2,5 \%$ de material fora da especificação. É praxe o engenheiro pedir ao técnico que peneire a amostra nas 
peneiras especificadas para medir a fração de material fora da especificação. Isso é uma boa prática porque materiais muito friáveis tendem a produzir finos durante 0 peneiramento, e o engenheiro deve estar a par deste problema e levar em consideração a influência desta fração nos cálculos relativos à determinação das taxas de moagem.

O material preparado de um determinado tamanho deve ser bem misturado, seco ao ar livre e armazenado num recipiente fechado.

\subsection{Ensaios Preliminares}

Estes ensaios são testes rápidos para determinar os tempos de moagem a serem usados nos ensaios de caracterização. Uma amostra de peso previamente calculado, e de tamanho determinado, por exemplo $1,18 \times 0,850 \mathrm{~mm}$, é retirada de seu recipiente, então esta é adicionada ao moinho e em seguida, são adicionadas as bolas. Cerca de 100 gramas da amostra de alimentação também são retiradas do recipiente para novo peneiramento. O moinho é então rodado por um tempo curto de moagem, por exemplo, 2 minutos. O moinho é deixado em repouso por alguns minutos para assentar e, em seguida, esvaziado lentamente para evitar dispersão de poeira, retirando-se todas as partículas agregadas à parede do moinho. Coleta-se também as partículas agregadas às bolas que em seguida são recolocadas no moinho. O material coletado deve ser homogeneizado e cerca de 100 gramas deve ser retirado para realização de um peneiramento, através da pilha longa ou outra técnica de quarteamento. A preferência é por quarteadores rotativos.

As 100 gramas de material de alimentação são peneiradas a seco por 20 minutos para obter a fração de peso das partículas com tamanho menor do que a peneira de fundo $(0,850 \mathrm{~mm})$ que são produzidas pelo próprio peneiramento. Esta fração deve ser menor ou igual a 1\%, isto é, a geração de finos por peneiramento deve ser não mais do que uns poucos pontos percentuais. A fração em peso remanescente na alimentação é determinada (> 99\%). A amostra moída é peneirada de maneira semelhante e a fração em peso de material remanescente (não moído) é determinada.

Os dois valores obtidos são plotados num mesmo gráfico nas escalas log-linear, no tempo $t=0$ na escala linear para a amostra original e em $t=2$ minutos para a amostra moída por 2 minutos. A linha reta que une os dois pontos é usada para estimar o tempo de moagem adicional necessário para obter cerca $50 \%$ da amostra no intervalo de tamanho da amostra de alimentação.

A amostra de material moído analisada é adicionada de volta ao restante do material e, o material todo deve ser recolocado no moinho para uma nova etapa de moagem, de acordo com o tempo estimado. A amostragem e o peneiramento é repetido para obter a fração remanescente no intervalo de tamanho da amostra de alimentação. Este resultado é plotado no mesmo gráfico para o tempo total de moagem. O tempo adicional necessário para obter cerca de $90 \%$ da alimentação moída é determinado, e a re-mistura, a re-moagem, a re-amostragem e um novo peneiramento devem ser realizados para obter a fração real de material moído. Nesta etapa final pode ser necessário lavar a amostra na peneira para uma determinação mais acurada das frações remanescente e passante. Sugere-se que uma análise granulométrica completa da amostra deva ser realizada ao final do teste preliminar.

Esta metodologia é repetida para o próximo tamanho menor de alimentação. Estes dados são suficientes para fazer uma estimativa preliminar aproximada dos parâmetros de quebra usando um simulador de moagem em batelada. Os objetivos 
são dois. O primeiro é obter tempos de moagem de forma que as diversas distribuições granulométricas obtidas para os tempos de moagem correspondentes estejam bem espaçadas. O segundo é obter uma distribuição granulométrica que atenda a especificação do circuito sendo escalonado no último tempo de moagem (por exemplo 80\% passante em 106 micrômetros para flotação).

\subsection{Ensaios de Caracterização}

Os mesmos tipos de ensaio agora são realizados com alimentação fresca, mas tomando muito cuidado para não perder as partículas menores por manuseio excessivo e grosseiro. As amostras a serem peneiradas são pesadas, e uma análise granulométrica completa é realizada pelo peneiramento a úmido. Após a secagem, a soma dos pesos deve ser próxima do peso original da amostra. Qualquer perda no peso é atribuída à fração menor que $0,045 \mathrm{~mm}$ (ou menor que 0,038 mm dependendo da série de peneiras utilizada nos ensaios. Como é habitual na realização de análises granulométricas completas, a massa da amostra para análise deve ser ajustada dependendo da quantidade de finos do produto, caso contrário, a quantidade excessiva de material fino pode interferir na eficiência do peneiramento. Uma regra razoável é não ter mais do que 5 a 10 gramas de material passante na peneira de $0,045 \mathrm{~mm}$, porém isso depende do material. Massas menores são recomendadas para materiais argilosos como bauxitas ou rochas altamente alteradas. Sendo assim, quatro tempos de moagem são especificados com base nos resultados dos ensaios preliminares de forma a obter-se: (a) não mais do que $30 \%$ de material moído; (b) cerca de 50-60\% de material moído; (c) 90-95\% de material moído e (d) um tempo maior para obter uma distribuição granulométrica do produto parecida com a distribuição granulométrica na descarrega do moinho industrial que está sendo escalonado. O tempo de moagem necessário para isso é estimado a partir dos resultados preliminares de simulação.

Os ensaios de caracterização são executados com os quatro tamanhos de alimentação. Dependendo dos resultados dos ensaios, analisados assim que os ensaios são realizados, é possível determinar se ensaios adicionais com outros tamanhos ou tempos de moagem serão necessários. Além disso, é habitual repetir alguns dos ensaios para obter uma medida de reprodutibilidade do procedimento.

\subsection{Moagem a Úmido}

Todos os ensaios acima relatados são realizados com moagem a seco. Sabe-se que a moagem a úmido, sendo as outras condições de moagem idênticas, apresenta o mesmo comportamento característico de quebra, porém as taxas específicas de quebra são aumentadas por um fator maior que 1 (1,3 de acordo com Bond) para o ensaio a úmido em relação ao ensaio a seco. Este fator pode ser determinado repetindo-se um dos ensaios de caracterização, usando uma proporção de sólidos/água igual a aproximadamente $40 \%$ em volume de sólidos e $60 \%$ em volume de água. O tamanho de partícula a ser testado deve ser próximo ao tamanho onde a taxa de moagem é mais alta $(1,18 \times 0,850 \mathrm{~mm}$ por exemplo, ou 1,70x1,18 mm). Os tempos de moagem dos ensaios a úmido devem ser os mesmos dos ensaios a seco. Os ensaios a úmido são muito demorados porque as amostras para análise granulométrica devem ser retiradas após a secagem de todo o material utilizado na moagem. A amostragem a úmido não é recomendada porque não funciona bem, em vista de que geralmente dá resultados irreproduzíveis. 


\subsection{Quantidades de Material}

Estima-se que a sequência de ensaio para um moinho de 250×250 mm requererá cerca de $10 \mathrm{~kg}$ de amostra de cada um dos tamanhos selecionados, por exemplo, $1,18 \times 0,850 \mathrm{~mm}, 0,425 \times 0,300 \mathrm{~mm}$ e cerca de $5 \mathrm{~kg}$ para as amostras de tamanho grande $(3,35 \times 2,36 \mathrm{~mm})$. A quantidade de alimentação dependerá da distribuição granulométrica da amostra. Se for mais conveniente, a amostra de tamanho $1,40 \times 1,00$ pode ser substituída por uma de $1,18 \times 0,850 \mathrm{~mm}$ assim como a amostra de $0,500 \times 0,355 \mathrm{~mm}$ que pode ser substituída por uma de 0,425×0,300 mm. Ou seja, a substituição por amostras em tamanhos adjacentes é sempre possível.

\section{RESULTADOS E DISCUSSÃO}

No caso do minério de ferro utilizado como exemplo, não foram necessários testes adicionais. A Figura 2 ilustra a função seleção determinada, as regiões de quebra normal e anormal e os tamanhos de partícula testados.

Pode-se observar na Figura 1 que as partículas maiores, 3,35×2,36 mm, encontramse na região de quebra anormal.

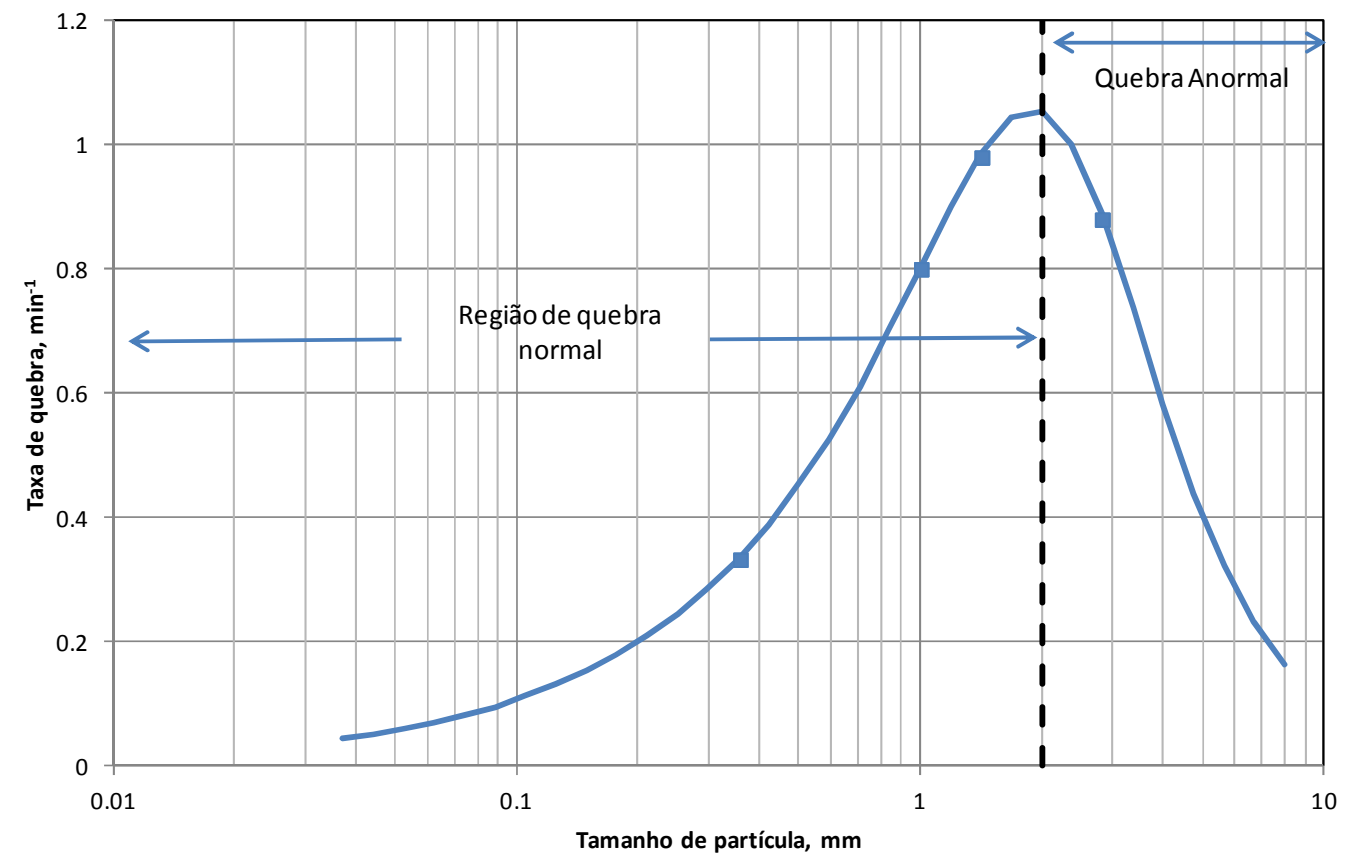

Figura 2: Taxas de quebra obtidas para a função seleção e tamanhos de partículas utilizadas nos ensaios do exemplo (minério de ferro)

Os tamanhos menores encontram-se na região de quebra normal, e a função seleção é determinada sem qualquer ambiguidade. O máximo da função seleção encontra-se em torno de 2,0 mm. Nestes casos, o escalonamento pode ser feito para qualquer tamanho de alimentação e qualquer tipo de carga de bolas, uma vez que a função seleção foi determinada nas duas regiões.

Quando todos os tamanhos testados encontram-se na região de quebra normal, o escalonamento só válido para cargas de bolas proporcionais ao tamanho máximo de partícula testado. Por exemplo, quando o ensaio é feito com bolas de $25 \mathrm{~mm}$ e a partícula maior do ensaio é de $2,5 \mathrm{~mm}$, o escalonamento de um moinho industrial 
com bolas de $50 \mathrm{~mm}$, por exemplo, pode ser feito para alimentações de até $5 \mathrm{~mm}$, proporcionalmente à alimentação e condições do teste.

Os ensaios de moagem produzem várias distribuições granulométricas, cada uma resultando de um tempo de moagem e de um tamanho inicial distinto. Os parâmetros de modelo são obtidos implementando-se a solução da equação de moagem em batelada com os modelos das funções quebra e seleção. Os parâmetros são então determinados minimizando-se a diferença entre os produtos previstos e os medidos. Este tópico é um tanto complexo e será tema de uma publicação em separado para um evento científico.

Com os parâmetros devidamente determinados, é possível escalonar, preferencialmente com ajuda de um software de simulação como pro exemplo o Modsim $^{\mathrm{TM}}$ [3], que têm implementado o modelo de escalonamento de Austin para moinhos de bolas.

\section{CONCLUSÃO}

O objetivo aqui era basicamente estabelecer a rotina de caracterização para o sistema de escalonamento de moinhos de Austin. Este objetivo foi atingido.

É difícil estabelecer uma rotina de testes padrão para estes ensaios, como por exemplo o ensaio de Bond. Neste sistema, o moinho não é padronizado, e há um número relativamente grandes de alternativas em função dos objetivos dos ensaios. Por outro lado, os procedimentos fazem sentido na medida em que os processos de moagem são melhor descritos e entendidos. Experiência prática é fundamental, e quanto maior a experiência, melhor e mais robustos serão os resultados e os escalonamentos realizados. No entanto, por melhor que seja a caracterização, o método de escalonamento de Austin requer um ensaio piloto para calibração. Isso ocorre porque o método é bastante flexível, permitindo escalonar praticamente todas as variáveis envolvidas no processo de moagem. Como resultado, existem várias "regras" ou equações/parâmetros de escalonamento e estes parâmetros podem necessitar uma calibração adicional. Além disso, o fato de testarmos partículas de monotamanho pode mascarar interações importantes entre os diversos tamanhos de partículas existentes na carga, e alguns ajustes podem ser necessários nos próprios parâmetros derivados da caracterização. O método de escalonamento de HerbstFuerstenau [4] é mais robusto neste aspecto.

\section{Agradecimentos}

Os autores agradecem à Norsk-Hydro pelo contínuo suporte para pesquisa, desenvolvimento e inovação em cominuição no CETEM.

\section{REFERÊNCIAS}

1 Austin, L. G., Klimpel, R. R., Luckie, P. T. Process Engineering of Size Reduction, SME - AIME, 1984.

2 Bond, F.C. Crushing and grinding calculations. Part I, British Chemical Engineering, 1961, 6:382.

3. Modsim $^{T M}$ - MODular SIMulator for Mineral Processing Plants, Manual do Usuário, $12^{\mathrm{a}}$ MTII - Mineral Technologies International, Inc Edição, 2009.

4 Herbst J. A. and Fuerstenau D. W. Mathematical Simulation of Dry Ball Milling using Specific Power Information, Trans. AIME, 1973, (254), pp. 343. 